\title{
Leitura e desempenho escolar em português e matemática no ensino fundamental
}

\author{
Katya Luciane de Oliveira \\ Universidade São Francisco, Itatiba-SP, Brasil \\ Evely Boruchovitch \\ Universidade Estadual de Campinas, Campinas-SP, Brasil \\ Acácia Aparecida Angeli dos Santos \\ Universidade São Francisco, Itatiba-SP, Brasil
}

\begin{abstract}
Resumo: O presente estudo objetivou explorar a relação entre compreensão em leitura e desempenho escolar em alunos do ensino fundamental de escolas públicas. Participaram 434 estudantes matriculados nas $5^{\mathrm{a}}, 6^{\mathrm{a}}, 7^{\mathrm{a}}$ e $8^{\mathrm{a}}$ séries. Aplicou-se, coletivamente, o Teste de Cloze. As notas escolares das disciplinas de português e matemática foram obtidas junto às secretarias de cada instituição. Os resultados revelaram associação entre compreensão em leitura e desempenho escolar. Alunos que demonstraram melhor compreensão textual também apresentavam desempenho escolar mais satisfatório em ambas as disciplinas. Esses dados foram discutidos à luz das implicações positivas que a compreensão em leitura tem para a aprendizagem de diferentes conteúdos escolares.
\end{abstract}

Palavras-chave: Teste de Cloze. Desempenho acadêmico. Compreensão da leitura. Ensino fundamental.

\section{Reading and school performance in portuguese and mathematics in elementary school}

\begin{abstract}
This study aimed to explore the relation between reading comprehension and schooling performance in portuguese and mathematics in primary education at public schools. The sample was composed by 434 students enrolled in $5^{\text {th }}, 6^{\text {th }}, 7^{\text {th }}$ and $8^{\text {th }}$ grades. The traditional Cloze test was collectively administered. Students' Portuguese and Mathematics grades were obtained in their school records. Results evidenced associations between reading comprehension and schooling performance. Students who presented better reading comprehension scores were those who presented satisfactory performance in both subjects. Data are discussed considering positive implications reading comprehension can have on learning several academic contents.
\end{abstract}

Keywords: Cloze Testing. Academic achievement. Reading comprehension. Fundamental education.

\section{Lectura y desempeño escolar en portugués y matemáticas en la enseñanza fundamental}

Resumen: El objetivo de este estudio fue explorar la relación entre comprensión en lectura y desempeño escolar en alumnos de la enseñanza fundamental de escuelas públicas. Participaron 434 estudiantes matriculados en las $5^{\mathrm{a}}, 6^{\mathrm{a}}, 7^{\mathrm{a}}$ y $8^{\mathrm{a}}$ series. Se aplicó, colectivamente, el teste de Cloze. Las notas escolares de las disciplinas de portugués y matemáticas fueron obtenidas junto a las secretarias de cada institución. Los resultados revelaron asociación entre comprensión en lectura y desempeño escolar. Alumnos que demostraron mejor comprensión textual también presentaron desempeño escolar más satisfactorio en ambas las disciplinas. Estos datos fueron discutidos a la luz de las implicaciones positivas que la comprensión en lectura tiene para el aprendizaje de diferentes contenidos escolares.

Palabras clave: Test de Cloze. Desempeño académico. Compresión de lectura. Educación primaria. 
Autores como Fini e Calsa (2006) e Sisto e Martinelli (2006) consideram que houve um crescimento do fracasso escolar no ensino fundamental, especialmente na última década. Tal fato pode ser atribuído às dificuldades de aprendizagem dos diferentes conteúdos escolares. O fracasso escolar se refere a um desempenho não satisfatório na aprendizagem das disciplinas. Embora muitas teorias busquem compreender suas causas, é sabido que no ensino fundamental ele envolve, sobretudo, problemas nos domínios da escrita e da leitura. Nessa direção, os dados obtidos pelo Indicador Nacional de Alfabetismo Funcional (INAF), do Instituto Paulo Montenegro (2007) sobre leitura, escrita e matemática no ano de 2007 , apontaram que somente $27 \%$ da população brasileira pode ser considerada plenamente alfabetizada.

No que tange à leitura, observa-se que muitos alunos do ensino fundamental apresentam sérias dificuldades nessa habilidade. Os estudantes que completam o ensino fundamental, isto é, chegam até a $8^{\mathrm{a}}$ série, por vezes, sabem ler. Contudo, não demonstram capacidade de abstrair as idéias mais relevantes do texto, apenas apresentam capacidade de decodificação simples, o que não significa que a compreensão tenha ocorrido. Há fortes chances que, ao ingressarem no ensino médio, esses alunos não terão a capacidade de leitura crítica e reflexiva, tão desejada para esse nível de escolaridade (Oliveira, 2005; Silva, 2004).

Essa situação lastimável é retratada em um levantamento realizado pela Organization for Economic Co-Operation and Development (2001), o qual indicou que $55 \%$ dos alunos do ensino fundamental brasileiro, matriculados nas $7^{\mathrm{a}}$ e $8^{\mathrm{a}}$ séries têm pouca ou nula compreensão em leitura. Em decorrência, sabe-se que a baixa ou nenhuma compreensão textual gera leitores pouco habilidosos na formulação de críticas, além de apresentarem sérios problemas para falar ou escrever utilizando a norma culta da língua. Conforme afirmam Cunha e Santos (2006), a compreensão em leitura, além de possibilitar pensamento crítico, facilita o domínio culto da língua, favorecendo a reflexão metalingüística.

Considerando a existência de muitas abordagens que explicam a compreensão em leitura, é importante ressaltar que na presente pesquisa adotou-se a teoria do processamento da informação como suporte teórico. Autores como Johnson e Hasher (1987), Nicholson (1999) e Woolfolk (2000) discutem que o processamento da informação diz respeito à capacidade do indivíduo adquirir, representar, armazenar e recuperar uma dada informação. A recuperação de uma informação já conhecida serve como elemento discriminador para que uma nova informação seja aperfeiçoada, viabilizando a aprendizagem.

Conforme afirmam Kintsch (1994) e Kintsch e Dijk (1978) a compreensão da leitura depende da inter-relação entre vários processos cognitivos. Apenas processos básicos como o reconhecimento de palavras e extração do significado das palavras impressas não são suficientes para a compreensão textual bem sucedida. Os autores insistem que são os processos cognitivos de alto nível, incluindo a capacidade de realizar inferências, habilidades de memória e o conhecimento de mundo que, de forma integrada, permitem ao leitor a representação macroestrutural do texto. No mesmo sentido, mas referindo-se ao processo de aprendizagem de forma geral, Pozzo (1998) observa que o cerne do processo está na capacidade de a pessoa representar mentalmente aspectos do mundo para poder operar sobre eles. A aprendizagem é, pois, um processo contínuo que envolve aspectos como ambiente, emoções, valores e constante aprimoramento.

Nessa perspectiva, pode-se considerar que a compreensão em leitura é um comportamento cognitivo verbal, em que o processamento da compreensão se inicia quando o leitor toma contato com algum novo conteúdo. Inicialmente, a memória de trabalho será ativada de modo a captar as informações textuais. Em seguida, analogias com informações já armazenadas na memória de longa duração serão realizadas. O leitor passa, então, a compreender a nova informação de modo que agora esta ficará arquivada, aguardando alguma oportunidade de ser acessada (Sternberg, 2000).

Sob esse aspecto, é possível fomentar que quanto mais contato se tem com a leitura, isto é, quanto mais se lê, mais aprimorada se torna a habilidade de compreensão, em razão do desenvolvimento e ampliação dos conhecimentos prévios que servirão de base para 
a compreensão de novas informações. Portanto, a compreensão envolve uma estreita relação entre o leitor e a leitura e depende de decodificação e compreensão linguística (Dembo, 2000; Hall, 1989; Spira, Bracken, \& Fischel, 2005).

Oliveira e Santos (2005) discutem que a compreensão em leitura vai além da capacidade de decodificar os símbolos do alfabeto. Envolve, pois, reflexão, crítica, pensamento analógico, atribuição de significado, capacidade de contextualização, ritmo e velocidade, entre outros aspectos, como a formação de atitudes positivas em relação à leitura e ao hábito de ler (Oliveira, Santos, \& Oliveira, 2007a, 2007b). Todos esses comportamentos formam um leitor competente e fluente na habilidade da leitura com compreensão.

Guterman (2003) aborda que somente com um bom conhecimento acerca do próprio processo de aprender é que o leitor consegue discriminar quando não compreendeu alguma nova informação. Pode-se supor que quando o aluno apresenta um bom repertório de conhecimentos armazenados, possivelmente, apresentará melhor compreensão, pois a compreensão em leitura depende de retroalimentação. As crianças que receberam mais estímulos positivos ambientais e afetivos em relação à realização da leitura apresentarão menor probabilidade de fracassar e demonstrarão melhor desempenho acadêmico (Gilabert, Martinez, \& Vidal-Abarca, 2005; Nicholson, 1999).

Autores como Gonida, Kiosseoglou e Leondari (2006) e Sailor e Abreu (2005) discutem que as crianças cognitivamente competentes são aquelas que apresentam planejamento, monitoramento e regulação do próprio processo de aprendizagem. Essas crianças, além de apresentarem uma boa compreensão em leitura, também têm um desempenho escolar muito mais satisfatório. Para Oliveira, Boruchovitch e Santos (2007), a compreensão em leitura e o desempenho acadêmico são aspectos que devem receber muita atenção por parte das instituições de ensino. Esse fato se justifica, tendo em vista que uma habilidade de compreensão textual falha pode levar a lacunas na aprendizagem dos diferentes conteúdos escolares e, conseqüentemente, ao baixo desempenho escolar.
O bom desempenho acadêmico, segundo Borkowiski (1992), se refere ao fato do aluno realizar as tarefas e as atividades escolares de forma eficaz, atingindo seu objetivo final que é o aprendizado. Contudo, é sabido que muitos alunos das diferentes etapas do ensino formal apresentam um desempenho escolar muito aquém do ideal. Quando se reflete sobre o desempenho escolar, há que se levar em consideração diferentes fatores que se correlacionam e influenciam diretamente tal desempenho. Dentre os fatores mais relevantes estão as características da escola, da família e do aluno. No primeiro caso se leva em consideração as condições físicas e pedagógicas da instituição escolar e dos profissionais que atuam nesse contexto. No segundo, enfatiza-se o nível escolar dos pais e sua presença e participação na aprendizagem dos filhos. Por fim, encontram-se as características pessoais do próprio aluno como motivação, boa auto-estima, habilidades sociais, possíveis deficiências nutricionais, entre outros (Formiga, 2004; Pastura, Mattos, \& Araújo, 2005).

Os resultados da avaliação da aprendizagem e que expressam o desempenho escolar, segundo Sant'anna (1995), são representados por critérios ordinais e classificatórios que podem ser de acordo com números, como é o caso das notas de 0 a 10 ou de 0 a 100, entre outros. Outro critério é o nominal, que abarca letras (A, B, C, D) ou níveis de aproveitamento (excelente, ótimo, bom, regular e péssimo). Por vezes, quando o aluno não consegue obter um bom desempenho escolar, ele é discriminado pela escola e pela família, o que pode exercer um impacto negativo em sua aprendizagem futura.

Freitas e Rocha (2003) consideram que o baixo desempenho escolar pode ser fonte geradora de conflitos. Se não houver fatores interferentes de modo a remediar a situação, a criança pode abandonar a escola. Nessa direção, argumenta-se que nas séries do ensino fundamental a compreensão em leitura é fundamental para todas as formas de aquisição de conhecimento. Assim, aqueles alunos que apresentam dificuldades de leitura ou lêem, mas não demonstram compreensão, certamente terão dificuldades no aprendizado de diferentes conteúdos escolares.

Estudos evidenciaram relação significante e positiva entre a compreensão em leitura avaliada por 
meio da técnica de Cloze e o desempenho acadêmico (Centofanti, Ferreira, \& Del Tedesco, 1997; Oliveira \& Santos, 2005, 2006; Oliveira, Santos, \& Primi, 2003; Santos, 1990, 1991; Santos, Primi, Taxa, \& Vendramini, 2002). Ao que parece, quanto melhor é a compreensão em leitura dos estudantes, maior é o seu desempenho acadêmico nas diferentes disciplinas escolares. Embora esses dados sejam relevantes, tais estudos investigaram predominantemente universitários.

As pesquisas realizadas com crianças (Boruchovitch, 2001; Braga, 1981; Gomes \& Boruchovitch, 2005; Oliveira e cols., 2007; Santos, Rueda, \& Bartolomeu, 2006; Zucolloto \& Sisto, 2002) focaram a compreensão em leitura e outros construtos, denunciando inclusive a baixa compreensão em leitura. Entretanto, não enfatizaram pontualmente a relação entre a compreensão em leitura e o desempenho acadêmico. Considerando que é no ensino fundamental que as primeiras dificuldades de leitura aparecem, há necessidade da realização de pesquisas que se proponham a averiguar melhor a possível relação entre a compreensão em leitura e o desempenho escolar nessa etapa da educação formal.

Tendo em vista as considerações trazidas, aventa-se a hipótese de que as crianças que apresentam uma leitura com compreensão, terão um bom desempenho escolar. Assim sendo, explorar a relação entre compreensão em leitura e desempenho escolar nas disciplinas de português e matemática em alunos das $5^{\mathrm{a}}, 6^{\mathrm{a}}, 7^{\mathrm{a}}$ e $8^{\mathrm{a}}$ séries do ensino fundamental de escolas públicas foi o objetivo deste estudo.

\section{Método}

\section{Participantes}

Participaram do presente estudo 434 estudantes provenientes de escolas públicas de duas cidades do interior do estado de São Paulo. Todas as escolas eram de porte médio, com boa estrutura física, atendendo aproximadamente 1200 alunos nos diferentes turnos de funcionamento. Embora estivessem localizadas na região central das cidades, também recebiam alunos residentes na área periférica. A coleta foi realizada no ano de 2005 com os alunos matriculados nas $5^{\mathrm{a}}(23 \%, n=100), 6^{\mathrm{a}}(31,3 \%, n=136), 7^{\mathrm{a}}(22,8 \%$, $n=99)$ e $8^{\text {a }}(22,8 \%, n=99)$ séries do ensino fundamental, matriculados nos períodos da manhã e da tarde. A média de idade foi de 12 anos e 9 meses $(D P=1,2)$, a idade mínima foi de 10 anos e a máxima 16 . O gênero masculino representou $46,5 \%(n=202)$ da amostra e o feminino $53,5 \%(n=232)$. Cabe esclarecer que se constituiu amostra por conveniência.

\section{Instrumento}

Foi utilizado o Teste de Cloze para a avaliação da compreensão em leitura. O teste foi criado em 1953 por Taylor. Em sua versão tradicional, se refere à omissão sistemática de todos os vocábulos múltiplos de cinco de um texto de 250 palavras, sendo que no local é colocado um traço de tamanho proporcional ao da palavra deletada. Trata-se de um instrumento bastante utilizado para mensurar a habilidade de compreensão em leitura em âmbito nacional e internacional. O texto utilizado e preparado segundo a técnica de Cloze foi o de autoria de Santos (2003), cujo título era 'Coisas que acontecem' e estava direcionado às crianças de $5^{\mathrm{a}}$ a $8^{\mathrm{a}}$ séries. $\mathrm{O}$ texto possuía aproximadamente 250 vocábulos e 40 omissões.

\section{Critérios de Avaliação}

Quanto ao número de acertos obtidos no Teste de Cloze, a pontuação no Cloze corresponde ao número de respostas corretas. Se um texto apresentar 40 omissões, o número de lacunas completadas corretamente corresponderá ao número de pontos obtidos (Taylor, 1956). Desse modo, utilizou-se a correção literal que aceitou como acerto o preenchimento exato da palavra omitida. Bormuth (1968) propõe níveis para classificar a pontuação no Cloze, sendo que o primeiro deles é o nível de 'frustração', que inclui leitores com até $44 \%$ de acertos, e considera que nesses casos não há compreensão em leitura. O segundo é o nível 'instrucional' e abrange a faixa de acertos de $44,1 \%$ a $57 \%$, referindo-se àqueles leitores que necessitam de ajuda externa para alcançarem a compreensão, pois demonstram compreensão apenas suficiente para entender algumas idéias trazidas no texto. O último nível é o 'independente' e engloba os leitores com aproveitamento superior a 
57\% dos acertos, demonstrando compreensão crítica, criativa e autônoma do texto.

Notas escolares referem-se aos conceitos obtidos pelos alunos nas disciplinas Português e Matemática, cujo registro constava nas secretarias das instituições de ensino. Vale esclarecer que foram utilizados os conceitos relativos ao bimestre letivo no qual a pesquisa foi realizada que eram expressos por meio das expressões, a saber, Realiza plenamente, Realiza e Em processo.

\section{Procedimento}

Todos os procedimentos éticos foram seguidos e estão em conformidade com a Resolução 196/96 do Conselho Nacional de Saúde e seus anexos. Portanto, esta pesquisa foi aprovada pelo Comitê de Ética em Pesquisa da Faculdade de Ciências Médicas da Universidade Estadual de Campinas. Inicialmente todos os responsáveis legais dos estudantes foram esclarecidos dos objetivos do estudo, a participação da criança ficou condicionada à assinatura do Termo de Consentimento Livre e Esclarecido pelos responsáveis legais.

As coletas ocorreram de forma coletiva em dia e horário estabelecidos pelas instituições de ensino. No dia da coleta a pesquisadora apresentou os objetivos do estudo para os alunos e esclareceu eventuais dúvidas. Em linhas gerais as instruções foram as seguintes: "Será apresentado um texto de aproximadamente 250 palavras, sendo que algumas palavras foram omitidas. Leia todo o texto, em seguida volte completando as lacunas com as palavras que você acredita serem adequadas ao contexto". Cada aplicação durou em média 30 minutos.

\section{Resultados}

Os dados foram organizados em planilha e submetidos às estatísticas descritiva e inferencial, visando atender o objetivo deste estudo. Primeiramente averiguou-se a pontuação obtida no Teste de Cloze. Os dados revelaram que a média de pontos foi de $21,8(D P=6,2)$, a pontuação mínima foi 0 e a máxima 33 pontos. Realizou-se um levantamento das médias e dos desvios-padrão no Teste de Cloze nas diferentes séries escolares. A Tabela 1 apresenta a descrição dos dados.
Tabela 1

Médias e desvios-padrão no teste de Cloze, por série escolar

\begin{tabular}{ccccc}
\hline Séries & $\boldsymbol{M}$ & $\boldsymbol{D P}$ & $\begin{array}{c}\text { Pontuação } \\
\text { Mínima }\end{array}$ & $\begin{array}{c}\text { Pontuação } \\
\text { Máxima }\end{array}$ \\
\hline $5^{\text {a }}$ & 18,6 & 6,4 & - & 29 \\
$6^{\mathrm{a}}$ & 22,6 & 4,7 & 5 & 34 \\
$7^{\mathrm{a}}$ & 22,4 & 5,7 & - & 32 \\
$8^{\text {a }}$ & 25,3 & 5,2 & - & 33 \\
\hline
\end{tabular}

Para levantar as notas escolares não se trabalhou com dados de média e desvio-padrão, uma vez que as notas eram expressas por conceitos. Desse modo, avaliou-se o percentual de crianças em cada conceito. A Tabela 2 apresenta os dados do número de sujeitos e da porcentagem de crianças distribuídas em cada conceito.

\section{Tabela 2}

Distribuição do número e porcentagem de crianças em cada conceito escolar

\begin{tabular}{lcccc}
\hline \multirow{2}{*}{ Conceitos } & \multicolumn{2}{c}{ Português } & \multicolumn{2}{c}{ Matemática } \\
& $\boldsymbol{n}$ & $\boldsymbol{\%}$ & $\boldsymbol{n}$ & $\boldsymbol{\%}$ \\
\hline Realiza plenamente & 118 & 27,2 & 75 & 17,3 \\
Realiza & 282 & 65 & 292 & 67,3 \\
Em processo & 34 & 7,8 & 67 & 15,4 \\
\hline
\end{tabular}

Para explorar a relação entre compreensão em leitura e desempenho escolar nas disciplinas de português e matemática, recorreu-se à análise de variância, tal como apresentado na seqüência. Os dados revelaram que houve diferença significante entre os alunos que apresentam um bom desempenho escolar em Português e aqueles que não, em relação à pontuação no Teste de Cloze, considerando $F(2$, 431)=21,694; $p \leq 0,001$. O teste post-hoc de Tukey indicou que a diferença estava entre os alunos com conceito Em processo e Realiza $(p=0,008)$ e Em processo e Realiza plenamente $(p \leq 0,001)$ e Realiza e Realiza plenamente $(p \leq 0,001)$. A Figura 1 apresenta o Box-plot dos participantes, considerando o desempenho no Cloze e os conceitos na disciplina de português. 


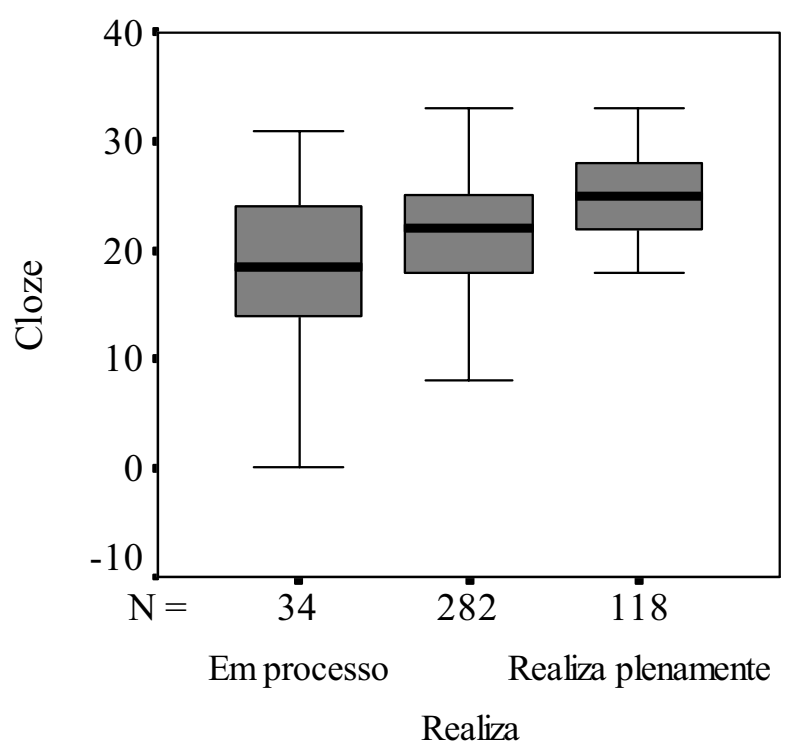

Português

Figura 1. Box-plot dos participantes, considerando o desempenho no Cloze e os conceitos na disciplina de português.

Os dados obtidos indicam que os alunos cujos conceitos na disciplina de Português eram Em processo tiveram uma média de pontuação no teste de Cloze mais baixa $(M=17,4)$ em relação aos alunos que tiveram os conceitos Realiza $(M=21,2)$ e Realiza plenamente $(M=24,6)$. O mesmo ocorreu para os alunos que tiveram o conceito Realiza em relação àqueles que obtiveram Realiza plenamente nessa disciplina.

No que concerne à disciplina de matemática, novamente a ANOVA demonstrou diferença estatisticamente significante entre os grupos $[F(2$, 431) $=12,190 ; p \leq 0,001]$. Pelo teste post-hoc de Tukey foi verificado que a diferença entre os escores médios obtidos no Cloze, com base no desempenho escolar na disciplina de matemática, ocorreu entre os alunos que tiveram os conceitos Em processo e Realiza ( $p \leq 0,001)$, Em processo e Realiza plenamente $(p \leq 0,001)$ e Realiza e Realiza plenamente $(p=0,024)$. Na Figura 2, pode-se observar o Box-plot dos participantes, considerando o desempenho no Cloze e os conceitos na disciplina de matemática.

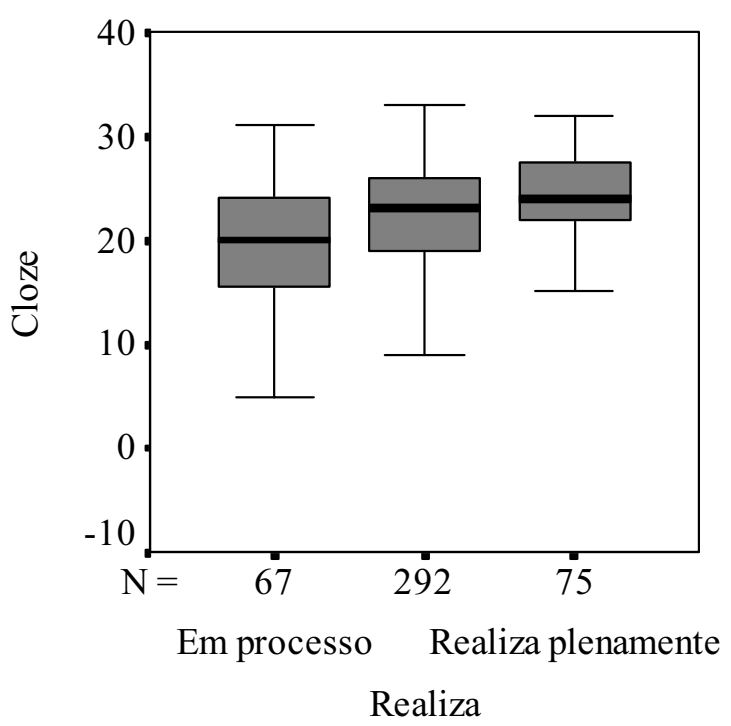

Matemática

Figura 2. Box-plot dos participantes, considerando o desempenho no Cloze e os conceitos na disciplina de matemática.

Esses dados demonstram que os alunos que na disciplina de Matemática tiveram o conceito Em processo $(M=19)$ se saíram pior no Cloze em relação àqueles que tiveram os conceitos Realiza $(M=21,9)$ e Realiza plenamente $(M=24,1)$. Acrescenta-se que essa mesma tendência ocorreu entre os alunos com desempenho Realiza e aqueles com o desempenho Realiza plenamente.

\section{Discussão}

A compreensão em leitura dos participantes pode ser considerada, segundo Bormuth (1968), no nível instrucional, visto que a média de pontos de 21,8 corresponde a aproximadamente $54,5 \%$ de acertos. Nesse nível estão os leitores que demonstram abstração apenas suficiente para compreender algumas idéias trazidas no texto, necessitando de auxílio externo para que a compreensão integral ocorra. Não é possível, contudo, observar comportamentos associados à criatividade, crítica e autonomia. Pondera-se ainda que, conforme mostram os resultados obtidos, parece haver uma progressão na melhora da compreensão em leitura com o passar dos anos 
escolares, especialmente, quando se observa $5^{\mathrm{a}}$ e a $8^{a}$ série que correspondem, respectivamente, ao início e ao final da segunda etapa do ensino fundamental. Evidentemente que os dados apresentados são exploratórios, carecendo de investigações mais aprofundadas.

Considera-se que esses resultados são positivos, tendo em vista que Silva (2004), Oliveira (2005) e a Organization for Economic Co-Operation and Development (2001) apontam que os alunos do ensino fundamental, sobretudo, aqueles que chegam à $7^{\mathrm{a}} \mathrm{e}$ $8^{a}$ séries, apesar de saberem ler, não apresentam abstração do conteúdo lido e, portanto, não compreendem o texto. Nessa direção, não se descarta o fato de que grande parte do alunado do ensino fundamental apresenta sérias dificuldades de compreensão em leitura. No entanto, adotando-se os parâmetros de Bormuth (1968), tal como feito na presente pesquisa, pode-se constatar que os estudantes não se saíram tão mal, mesmo porque a pontuação média indica que eles conseguiram alcançar mais da metade de acertos possíveis no Cloze.

Para Dembo (2000), Hall (1989), Spira e cols. (2005), a leitura serve de base para a aquisição de novos conhecimentos por permitir a ampliação dos conhecimentos já armazenados na memória de longa duração, salientando a importância de uma boa relação entre leitor e leitura. Assim sendo, há necessidade de que as instituições de ensino adotem programas, especificamente destinados ao aprimoramento e à motivação para a leitura, não só em sala de aula, mas também como forma de lazer. Infelizmente nas escolas nas quais a pesquisa foi realizada não havia nenhuma iniciativa dessa natureza. Reforça-se, pois, a importância da implemenação de programas de desenvolvimento da leitura, já que mesmo se tratando de alunos do ensino público oriundos da classe socioeconômica desfavorecida, foi possível observar um percentual razoável de alunos que com algum tipo de ajuda externa de professores ou monitores poderiam ler compreensivamente.

No que concerne ao desempenho escolar nas disciplinas de Português e Matemática, observou-se que a maior parte dos alunos obteve em ambas um conceito expresso em Realiza. Os extremos indicam que uma parte dos estudantes consegue um conceito
Realiza plenamente, sobretudo na disciplina Português, e também denunciam que outra parte está $E m$ processo, o que denota um desempenho insatisfatório. As considerações trazidas por Freitas e Rocha (2003) e Sant'anna (1995) remetem ao fato de que os alunos que não conseguem obter um bom desempenho escolar, possivelmente, serão discriminados e cobrados pela família, escola e colegas.

No caso da disciplina Português, os alunos com conceito Realiza plenamente também foram aqueles que melhor compreenderam o texto, correspondendo ao nível independente de leitura com aproveitamento médio de $64,5 \%$ de acertos. Aqueles que tiveram o conceito Realiza demonstraram abstração apenas suficiente (média de 53\% de acertos), isto é, estavam incluídos no nível instrucional. Por fim, os alunos que estavam Em processo tiveram baixa compreensão textual (média de 43,5\% de acertos) e foram inseridos no nível de frustração, pois não demonstraram nenhuma compreensão da informação lida.

Resultados semelhantes foram observados na disciplina Matemática, pois os alunos com conceito Em processo também foram aqueles que demonstraram menor compreensão em leitura, isto é, nível instrucional com aproveitamento médio de 47,5\% de acertos. Os alunos com conceito Realiza também estavam no nível instrucional com 54,7\% de aproveitamento médio e aqueles que apresentaram o conceito Realiza plenamente acertaram em média aproximadamente $60,2 \%$ e demonstraram compreensão independente. Nesse sentido, as considerações trazidas por Freitas e Rocha (2003) e Sant'anna (1995) remetem ao fato de que os alunos que não conseguem obter um bom desempenho escolar, possivelmente, serão discriminados e cobrados pela família, escola e colegas.

Por meio da ANOVA, foi possível aferir associação entre nível de compreensão textual e desempenho escolar no ensino fundamental, considerando que os grupos de alunos se diferenciaram em relação à compreensão. Essas observações são congruentes com as considerações de Formiga (2004) e Pastura e cols. (2005) sobre o quanto a compreensão em leitura pode minimizar as dificuldades escolares e, conseqüentemente, melhorar o desempenho escolar. 


\section{Considerações finais}

Tomando por base a literatura recuperada sobre o tema, insiste-se no fato de que alunos do ensino fundamental poderiam melhorar ainda mais sua compreensão em leitura, se projetos interventivos que visassem remediar as dificuldades ou aprimorar essa habilidade fossem realmente desenvolvidos. Sem dúvida os resultados pífios apresentados pelos alunos brasileiros, quando comparados ao desempenho de crianças de outros países, poderiam estar em patamares superiores, se houvesse um investimento de monta para incrementar a sua compreensão textual. Certamente, uma melhor compreensão em leitura teria reflexos positivos na ampliação dos demais conhecimentos.

Em acréscimo, ressalta-se que a compreensão em leitura, por funcionar como fator de retroalimentação e de forma macroestrutural, ainda contribuiria para a aprendizagem de diferentes conteúdos escolares. Assim, facilitaria a utilização de processos cognitivos complexos, tais como o raciocínio analógico e o analítico, exigidos pela disciplina de matemática, por exemplo.

Se há muitos fatores implicados na obtenção de um bom desempenho escolar, fortalecer a compreensão em leitura poderia minimizar as dificuldades escolares e, conseqüentemente, melhorar o desempenho escolar. Em síntese, retoma-se a idéia de que as instituições de ensino deveriam dar mais atenção a essa importante habilidade. Acredita-se que com isso muitos problemas poderiam ser evitados, especialmente o baixo desempenho escolar, a dificuldade de apreensão dos diferentes conteúdos escolares, bem como o fracasso escolar.

Por fim, destaca-se que muitos dos estudos aqui mencionados examinaram a relação entre a compreensão em leitura e o desempenho escolar, predominantemente, com universitários. Recomenda-se, portanto, que novas pesquisas com objetivos similares sejam realizadas em diferentes séries do ensino fundamental.

\section{Referências}

Borkowski, J. G. (1992). Metacognitive theory: A framework for teaching literacy, writing and math skills. Journal of Learning Disabilities, 5(4), 253-257.
Bormuth, J. R. (1968). Cloze test readability: Criterion reference scores. Journal of Educational Measurement, 5, 189-196.

Boruchovitch, E. (2001). Estratégias de compreensão em leitura de alunos do ensino fundamental. Psicologia Escolar e Educacional, 5, 19-25.

Braga, S. M. L. (1981). Remediação da leitura: Um estudo com escolares de primeiro grau utilizando a Técnica Cloze. Dissertação de mestrado não-publicada, Instituto de Psicologia, Universidade de São Paulo, SP.

Centofanti, E. M., Ferreira, S. M., \& Del Tedesco, T. (1997). Compreensão da leitura por universitários de psicologia. In G. P. Witter (Org.), Leitura e universidade (pp. 33-60). Campinas, SP: Alínea.

Conselho Nacional de Saúde. (1996). Resolução 196/ 96. Diretrizes e Normas Regulamentadoras de Pesquisa. Recuperado em 19 outubro 2005, de http://www.conselho.saude.gov.br

Cunha, N. B., \& Santos, A. A. A. (2006). Relação entre a compreensão da leitura e a produção escrita em universitários. Psicologia: Reflexão $e$ Crítica, 19, 237-245.

Dembo, M. H. (2000). Motivation and learning strategies for college success. New Jersey, NJ: Lawrence Erbaum Associates.

Fini, L. D. T., \& Calsa, G. C. (2006). Matemática e afetividade: Alunos desinteresados no ensino fundamental? In F. F. Sisto \& S. C. Martinelli (Orgs.), A afetividade e dificuldades de aprendizagem (pp. 163-180). São Paulo: Vetor.

Formiga, N. S. (2004). O tipo de orientação cultural e sua influência sobre os indicadores do rendimento escolar. Psicologia: Teoria e Prática, 6(1), 13-29.

Freitas, M. G., \& Rocha M. M. (2003). Atendimento a crianças com desempenho escolar insatisfatório. In C. G. Almeida (Org.), Intervenções em grupos: Estratégias psicológicas para a melhoria da qualidade de vida (pp. 11-21). Campinas, SP: Papirus. 
Gilabert, R., Martínez, G., \& Vidal-Abarca, E. (2005). Some good text are always better text revision to foster inferences of readers with high and low prior background knowledge. Learning and Instruction, 15-, 45-68.

Gomes, M. A. M., \& Boruchovitch, E. (2005). Desempenho no jogo, estratégias de aprendizagem e compreensão em leitura. Psicologia: Teoria e Pesquisa, 21, 319-326.

Gonida, E., Kiosseoglou, G., \& Leondari, A. (2006). Implicit theories of intelligence, perceived academic competence, and school achievement: Testing alternative models. American Journal of Psychology, 119, 223-238.

Guterman, E. (2003). Integrating written metacognitve awarencess guidance as a psychological tool to improve student performance. Learning and Instruction, 13, 633-651.

Hall, W. S. (1989). Reading comprehension. American Psychologist, 44, 157-161.

Instituto Paulo Montenegro. (2007). Indicador nacional de alfabetismo funcional. Recuperado em 15 fevereiro 2008, de http:// arquivo.portaldovoluntario.org.br/press/upl oadArquivos/122088926283.pdf

Johnson, M. K., \& Hascher, L. (1987). Human learning and memory. Annual Review of Psychology, 38, 631-668.

Kintsch, W. (1994). Text comprehension, memory and learning. American Psychologist, 49, 294-303.

Kintsch, W., \& Dijk, T. A. van (1978). Toward a model of text comprehension and production. Psychological Review, 85, 363-394.

Nicholson, T. (1999). Reading comprehension processes. In G. B. Thompson \& T. Nicholson (Eds.), Learning to read (pp. 127-149). Newark, NJ: IRA.

Oliveira, K. L., Boruchovitch, E., \& Santos, A. A. A. (2007). Compreensão de leitura em alunos de sétima e oitava séries do ensino fundamental. Psicologia Escolar e Educacional, 11, 41-49.
Oliveira, K. L., \& Santos, A. A. A. (2005). Compreensão em leitura e avaliação da aprendizagem em universitários. Psicologia: Reflexão e Crítica, 18, 118-124.

Oliveira, K. L., \& Santos, A. A. A. (2006). Compreensão de textos e desempenho acadêmico. Psic: Revista da Vetor Editora, 7(1), 19-27.

Oliveira, K. L., Santos, A. A. A., \& Oliveira, E. Z. (2007a). Atitudes de leitura e desesperança em idosos. Paidéia (Ribeirão Preto), 17, 245-254.

Oliveira, K. L., Santos, A. A. A., \& Oliveira, E. Z. (2007b). Estudo das propriedades psicométricas de uma escala de atitudes de leitura para universitários. Paradigma (Maracay), 28, 165-180.

Oliveira, K. L., Santos, A. A. A., \& Primi, R. (2003). Estudo das relações entre compreensão em leitura e desempenho em disciplinas na universidade. Revista Interação em Psicologia, 7, 19-25.

Oliveira, J. B. A. (2005). Avaliação em alfabetização. Ensaio: Avaliação e Políticas Públicas em Educação, 13, 375-382.

Organization for Economic Co-Operation and Development. (2001). Knowledge and skills for life: First results from the PISA 2000. Paris: OECD.

Pastura, G. M. C., Mattos, P., \& Araújo, A. P. Q. C. (2005). Desempenho escolar e transtorno do déficit de atenção e hiperatividade. Revista de Psiquiatria Clínica, 32, 324-329.

Pozo, J. I. (1998). Teorias cognitivas da aprendizagem (3a ed.). Porto Alegre: Artmed.

Sailor, K. M., \& Abreu, Y. (2005). The nature of memory errors for verbaly quantified information. American Journal of Psychology, 118, 235-250.

Sant'anna, I. M. (1995). Por que avaliar? Como avaliar? Critérios e instrumentos. Petrópolis, RJ: Vozes.

Santos, A. A. A. (1990). Compreensão em leitura na universidade: Um estudo comparativo entre dois procedimentos de treino. Estudos de Psicologia, 7(2), 39-53. 
Santos, A. A. A. (1991). Desempenho em leitura: Um estudo diagnóstico da compreensão e hábitos de leitura entre universitário. Estudos de Psicologia, 8(1), 6-19.

Santos, A. A. A. (2003). Coisas que acontecem. Texto preparado segundo a técnica de Cloze para crianças de $5^{a}$ a $8^{a}$ séries do ensino fundamental. Manuscrito não-publicado, Programa de Pós-graduação Stricto Sensu, Universidade São Francisco, Itatiba, SP.

Santos, A. A. A., Primi, R., Taxa, F., \& Vendramini, C. M. M. (2002). O Teste de Cloze na avaliação da compreensão em leitura. Psicologia: Reflexão e Crítica, 15, 549-560.

Santos, A. A. A., Rueda, F. J. M., \& Bartolomeu, D. (2006). Avaliação dos aspectos afetivos envolvidos nas dificuldades de aprendizagem. In F. F. Sisto \& S. C. Martinelli (Orgs.), Afetividade e dificuldades de aprendizagem (pp. 93-110). São Paulo: Vetor.

Silva, V. R. (2004). Estratégias de leitura e competência leitora: Contribuições para a prática de ensino em História. História (São Paulo), 23(1-2), 69-83.

Sisto, F. F., \& Martinelli, S. C. (2006). O papel das relações sociais na compreensão do fracasso escolar e das dificuldades de aprendizagem. In F. F. Sisto \& S. C. Martinelli (Orgs.), A afetividade e dificuldades de aprendizagem (pp. 13-30). São Paulo: Vetor.

Spira, E. G., Bracken, S. S., \& Fischel, J. E. (2005). Predicting improvement after first-grade reading difficulties: The effects of oral language, emergent literacy, and behavior skills. Developmental Psychology, 41, 225-234.

Sternberg, R. J. (2000). Psicologia cognitiva (M. R. Borges, Trad.). Porto Alegre: Artes Médicas.

Taylor, W. L. (1956). Recent development in the use of Cloze procedure. Journalism Quartely, 33, 42-46.

Zucoloto, K. A., \& Sisto, F. F. (2002). Dificuldades de aprendizagem em escrita e compreensão em leitura. Interação em Psicologia, 6, 157-166.

Woolfolk, A. (2000). Psicologia da educação. Porto Alegre: Artmed.
Artigo recebido em 29/05/2008.

Aceito para publicação em 05/12/2008.

As autoras agradecem ao $\mathrm{CNPq}$, cuja Bolsa de Produtividade em Pesquisa concedida às duas últimas autoras permitiu a realização da presente pesquisa.

Endereço para correspondência:

Profa. Dra. Acácia Aparecida Angeli dos Santos. Universidade São Francisco. Programa de Pós-graduação Stricto Sensu em Psicologia. Rua Alexandre Rodrigues Barbosa, 45. CEP 13251-040. Itatiba-SP, Brasil. E-mail: acacia.santos@saofrancisco.edu.br

Katya Luciane de Oliveira é Professora Assistente do curso de Psicologia da Universidade São Francisco.

Evely Boruchovitch é Professora Livre-docente da Faculdade de Educação da Universidade Estadual de Campinas.

Acácia Aparecida Angeli dos Santos é Professora Titular do Programa de Pós-graduação em Psicologia da Universidade São Francisco. 